\title{
AN OBSERVATIONAL STUDY OF TONGUE TIE RELEASE USING BIPOLAR DIATHERMY AT VELLORE DISTRICT IN TAMILNADU
}

\author{
Rangan Madana Gopal ${ }^{1}$
}

1Professor, Department of ENT, Government Vellore Medical College, Vellore, Tamilnadu, India.

\begin{abstract}
BACKGROUND
Ankyloglossia also known as the hypertrophic lingual frenulum, is a condition where there is a limitation to the tongue movement due to the congenitally short frenulum or there is a fibrous band between base of tongue and tongue. Its prevalence is around $0.4 \%$ to $4.8 \%$ in newborns. The objective of the study was to study the effects of tongue tie release using bipolar cautery under local anaesthesia.
\end{abstract}

ABSTRACT

\section{MATERIALS AND METHODS}

An observational study was done during January 2016 to June 2016. All the paediatric patients attending the ENT Department at Vellore Medical College who had given informed consent were included in the study. Data was collected by questionnaire and assessment was done post operatively. Data analysis was done by SPSS v20 and summarised by descriptive statistics.

\section{RESULTS}

Total number of patients included in the study was 75. Among them $47(63 \%)$ were boys, $28(37 \%)$ were girls. The age of patients ranges from 4-7 years, mean age was $5.59 \pm 1.03$ yrs. None of the patients had any complications during the procedure and post operatively.

\section{CONCLUSION}

This novel technique can be considered superior to all the conventional techniques.

\section{KEY WORDS}

Lingual Frenulum, Tongue Tie Release, Bipolar Diathermy.

HOW TO CITE THIS ARTICLE: Gopal RM. An observational study of tongue tie release using bipolar diathermy at Vellore District in Tamilnadu. J. Evolution Med. Dent. Sci. 2018;7(52):5535-5538, DOI: 10.14260/jemds/2018/1225

\section{BACKGROUND}

Ankyloglossia also known as the hypertrophic lingual frenulum, is a condition where there is a limitation to the tongue movement due to the congenitally short frenulum or there is a fibrous band between base of tongue and tongue. ${ }^{1}$ Frenotomy, or tongue tie division is the treatment for this condition.

In age old times, tongue tie release was done by midwives who tore the frenulum with their nails which was often dirty. They also stripped the tongue. This resulted in infection of oral cavity. The stripped-up tongue caused asphyxia by falling backward. Hemorrhage from lingual artery was also catastrophic. There was scar tissue formation and tongue became fixed in a pathological position. This procedure was abandoned in $20^{\text {th }}$ century due to many complications. ${ }^{2}$ Paulus Aegineta suggested release of tongue tie by cutting the frenulum transversely and making superficial incision to avoid haemorrhage ${ }^{3}$. There were many oppositions to frenulotomy and frenulectomy in the past due to complications and relapse.

The surgical techniques used are ripping with fingernail or instrument like iris scissors or scalpel, excision of frenulum and closure in horizontal direction, excision of

'Financial or Other Competing Interest': None.

Submission 20-11-2018, Peer Review 30-11-2018,

Acceptance 17-12-2018, Published 24-12-2018.

Corresponding Author:

Dr. Rangan Madana Gopal,

No. 3, Veerasamy Street,

Egmore, Tamilnadu, India.

E-mail: madrasmadan@gmail.com

DOI: $10.14260 /$ jemds/2018/1225

\section{(c) $(1) \ominus$}

frenulum and genioglossus and closure with z-plasty, electrocautery, cold surgery and laser surgery. Coblation surgery is a new technology.

The tongue appears in the embryo in 4 weeks of gestation as 2 lateral lingual swellings and one medial swelling, the tuberculum impar. These 3 swellings develop from the first pharyngeal arch. Another median swelling, the copula or hypobranchial eminence is formed by the mesoderm of second and third part of the fourth arch. The lateral lingual swellings increase in size, overgrow the tuberculum impar and merge forming the body of the tongue in anterior two third. Sensory innervation of mucosa covering the body of the tongue is by mandibular branch of trigeminal nerve as the mucosa originates from the first pharyngeal arch. Anterior two third of tongue is separated from posterior third by terminal sulcus.

Posterior third, or root of the tongue develops from second and third part of fourth pharyngeal arch. Third arch overgrows the second so the root is supplied by glossopharyngeal nerve. Superior laryngeal nerve innervates the epiglottis and extreme posterior part of tongue and they develop from fourth arch. Tongue muscles originates from myoblasts from occipital somites and innervated by hypoglossal nerve.

Extensive cell degeneration occurs and the frenulum only remains which anchors the tongue to the floor of the mouth. If the tongue is not freed from floor of mouth, it results in tongue tie. Usually frenulum extends upto the tip of the tongue. ${ }^{4}$

Ankyloglossia is another name for tongue tie. It varies in degree of severity from mild cases characterized by mucous membrane bands to complete ankyloglossia whereby the 
tongue is tethered to the floor of the mouth. ${ }^{5}$ It can affect feeding, speech, and oral hygiene as well as have mechanical/social effects. Its prevalence is around $0.4 \%$ to $4.8 \%$ in newborns, with a male to female ratio of $3: 1 .^{6}$ In many individuals, ankyloglossia is symptomatic and may resolve spontaneously, if not resolved then the affected individuals may learn to compensate adequately for their decreased lingual mobility.

According to the latest statistics there is a prevalence of 4 per 1000 population of children with ankyloglossia worldwide. In a study done in USA, in the University of Cincinnati published in 2002 there is a total prevalence of tongue tie in $18 \%$ of the total children population. In the UK, a study done at the Southhampton General Hospital showed tongue tie in $10 \%$ of the babies born there ${ }^{7}$. In the Indian scenario 12 babies per 1000 are affected by tongue tie according to a recent study in 2008.8

Tongue tie often is a neglected condition in rural scenario. Even in urban cities it is sometimes neglected due to heavy workload. The objective of the study was to study the effects of tongue tie release using bipolar cautery under local anaesthesia.

\section{MATERIALS AND METHODS}

An observational study was done during January 2016 to June 2016. All the paediatric patients attending the ENT Department with tongue tie at Vellore Medical College who had given informed consent were included in the study. Institutional ethical committee approval was obtained. Data collected by questionnaire and assessment was done post operatively. Data analysis was done by SPSS v20 and summarised by descriptive statistics.

\section{Materials}

$4 \%$ lignocaine, $1 \%$ lignocaine, distilled water, Babcock forceps, bipolar cautery.

\section{Methods}

Under local anaesthesia of topical application of $4 \%$ lignocaine and infiltration by half cc of $1 \%$ lignocaine diluted in half $\mathrm{cc}$ of distilled water on either side of the lingual frenulum, tongue is held using Babcock forceps and lifted towards the upper incisors to expose the lingual frenulum. The tip of the bipolar is used to cauterise the lingual frenulum very close to the tongue base avoiding the floor of the mouth. When the release point is reached, the area is packed with gauge soaked in $4 \%$ lignocaine to avoid post-operative pain.

\section{RESULTS}

Total number of patients included in the study was 75 . Among them $47(63 \%)$ were boys, $28(37 \%)$ were girls. The age of patients ranges from 4-7 years, mean age was $5.59 \pm 1.03$ yrs.

All the patients underwent tongue tie release using bipolar cautery under local anaesthesia were observed. The operating time ranges from 2-5 minutes. All the patients had an uneventful post-operative period. None of the patients had any complications of injury to the Warton's duct or bleeding from the lingual vein. It was absolutely bloodless surgery as bipolar was used. There was no requirement of using sutures and thus the complication of slippage of the knot and its complications were not there. In no time the whole procedure gets over as the procedure is a non-invasive technique done under local anaesthesia. Post-operative medication like antibiotics and anti-inflammatory medications were also not needed for these patients.

\begin{tabular}{|c|c|c|}
\hline Sl. No. & Complications & Results \\
\hline 1 & Post-Operative Pain & Nil \\
\hline 2 & Bleeding & Nil \\
\hline 3 & Oedema & Nil \\
\hline 4 & Scarring & Nil \\
\hline \multicolumn{2}{|c|}{ Table 1. Complications of Bipolar Cautery for Tongue Tie } \\
Release
\end{tabular}

\section{DISCUSSION}

All the patients had an uneventful post-operative period. Which is comparable to the study done by Gujarathi et al. ${ }^{9}$ Ankylos is a Greek word for fused and glossa for tongue. Ankyloglossia is the medical term for tongue tie. There are a wide range for methods by which the hypertrophied frenulum can be dissected. Also, wide range of opinions regarding the feeding problems, speech and other social issues.

According to Kotlow, tongue tie can be classified in reference to distance of insertion of lingual frenum to tip of tongue. 10

1. Normal - $16 \mathrm{~mm}$

2. Class I, mild - 12-16 mm;

3. Class II, moderate $8-12 \mathrm{~mm}$;

4. Class III, severe 4-8 $\mathrm{mm}$; and

5. Class IV, complete $0-4 \mathrm{~mm}$.

\section{The normal range of motion of tongue is suggested by the} following criteria-

1. The tip of the tongue should be capable of protruding outside the mouth without clefting,

2. The tip of the tongue should be capable of sweeping the upper and lower lips easily without straining,

3. When the tongue is retruded, it shall not blanch the tissues lingual to the anterior teeth

4. The lingual frenum shall not produce a diastema between the mandibular central incisors. ${ }^{11}$

The tongue is an accessory organ of interest useful for deglutition, speech and mastication. Also needed for dental occlusion, growth and facial form. At birth, it is short, and the frenulum extends till tip. During early weeks, the tongue grows thinner and longer. The frenulum stretches and the tongue attachment shrinks to a lower position.

Tongue plays a major role in the mechanism by which an infant removes milk from the breast. Milk flow from the nipple to infant's oral cavity is by lowering of tongue and vacuum created in the oral cavity. 12 The medial portion of the tongue where genioglossus is inserted moves in relation to lateral portion where styloglossus and hyoglossus are inserted. Peristaltic wave of inferior and superior displacement moves posteriorly in medial portion which compresses or milks the nipple and propels the expressed milk towards the pharynx. Lateral portion encloses the nipple and bolus of milk. ${ }^{13}$

In both the mechanisms by which an infant removes milk from the breast namely, 1. Compression of areola and peristaltic action of tongue, 2 . Creation of vacuum and up and 
down or piston like action of the tongue, tongue plays a major role in infant breastfeeding. ${ }^{14}$

Tongue tie causes breast feeding difficulties in infants. Early treatment improves breast feeding and allows infant to get all the long-term benefits of breast feeding. 15

In infants, the tongue is unconfined by the teeth. It extends outwards between the maxillary and mandibular arches. On swallowing, the jaws are parted, and tongue placed between gums which produces vacuum for suctioning. At 2 and half years, the infantile swallow is replaced by adult swallow where the lips are close, teeth is in occlusion, tip of tongue raised and pressed against anterior part of the palate, which seals the anterior portion of the mouth.

In some children, the infantile swallow persists. They swallow with jaws apart. Teeth are not occluded, and tongue thrust between dental arches. This results in open bite malocclusion. Bone growth and moulding are also affected by repeated stress and pressure like function, gravity and those applied by soft tissue. Well-proportioned tongue thrust which is repeated during deglutition in the maxilla and mandible helps in their forward and lateral growth. Tongue tie may result in early prognathism. This is an important indication for tongue tie release. In elderly, prominent lingual frenulum may dislodge denture when tongue is raised. ${ }^{16}$

Speech development starts from the day of birth or before that. Language acquisition develops from 12 months. Child starts to speak one or two meaningful words by 12 months. Sounds are the precursors of speech. Tongue is one of important structure in speech production. Hyoid bone and part of anterior and posterior suprahyoid muscles regulate the position of tongue relative to upper and lower jaws and angulation and length of the floor of mouth. The extrinsic tongue muscles along with the intrinsic muscles control the instantaneous shape of tongue. Each segment is innervated by branches of hypoglossal nerve. ${ }^{17}$

Sanguineti et al proposed that the tongue movement is due to a small number of tongue-articulators ${ }^{18}$. Ohman suggested 3 tongue articulators. Body (Front and back or up and down movement), apex (Tongue tip movement) and dorsum (Arching, flattening). ${ }^{19}$ Extrinsic muscles of tongue namely genioglossus, hyoglossus, styloglossus and palatoglossus are responsible for positioning the tongue in the oral cavity. Intrinsic muscles namely superior longitudinal, inferior longitudinal, transverse and vertical muscles are responsible for tongue shape. ${ }^{18}$ Movement of the tongue is by contraction of the muscles of tongue floor.

Tongue tie can cause speech disorders like stuttering, lisping and retardation in speech. Frenulectomy is indicated in these cases. During speech, th sound, n, t, d, s, z and l sounds may be difficult to produce. In tongue tie these are compensated by various methods. In surgical intervention, anteroposterior length of the frenulum and vertical shortness of the frenulum must be considered. By 18 months of age, the child starts to say sentences of 2-3 words. So tongue tie release has to be done before 18 months of age. 18

On microscopic examination of tongue tie, mucosa of frenulum is found to be fibrosed. Underlying fibres of genioglossus muscle is also replaced by fibrous tissue. ${ }^{20}$

Disease can be associated with $\mathrm{x}$-linked cleft palate, van der Voude syndrome and maternal cocaine abuse. Connection between mutation of TBX22 gene and ankyloglossia is documented in literature. 19
Frenectomy, frenulectomy and frenuloplasty are the described surgical methods. ${ }^{21}$ Dissection can be done using a surgical scissors, scalpel, cautery, laser and coblation. Here we have done tongue tie release using bipolar diathermy under local anaesthesia as a day care procedure. All the patients had good results.

Bipolar diathermy is used for performing delicate surgeries. It has two electrodes in a diathermy forceps. There is flow of current only through the tissue gripped in its tip. So there is greater accuracy, safety and less tissue damage. Diathermy uses radio frequency $300 \mathrm{kHz}$ to $3 \mathrm{MHz}$ alternating electric current. The passage of current through tissue produces heat. In bipolar the tissue is very less, so heating is reduced to minimum. In unipolar cautery, indifferent electrode must be placed. If the frequency is less $(50 \mathrm{~Hz})$, it results in intense activation of muscles. But high frequency from $300 \mathrm{kHz}$ to $3 \mathrm{MHz}$ can pass through tissue without activating muscles. In coagulation, it uses spark gap principle, which produces 100 blocks of energy per second at frequency $400 \mathrm{kHz}$. For cutting it uses valve oscillators which produces bursts of energy 50 times per second at frequency between $1.6 \mathrm{MHz}$ to $3 \mathrm{MHz}$. These interfere with EEG and ECG recordings.

Cautery can produce coagulation, fulguration and dissection or cutting. Coagulation is used to achieve haemostasis during surgery. This is by direct application of heat to the bleeding vessel which causes coagulation of blood proteins, drying out of vessel wall cells and shrinking and retraction of vessel ends. This leads to thrombus formation and occlusion of vessel. Fulguration is destructive coagulation of tissue. Used for coagulation and destruction of small growths in bladder or rectum. In dissection or cutting, the tissue is incised, and divided surfaces cauterised. A small sine wave passes through the tissue and produces a very hot cutting arc and results in bloodless field during surgery. 22

Advantages of electro-cautery observed are, the electrode cuts on its sides as well as on its tip, it meets the clinical need, haemostasis is immediate and consistent, the wound is nearly painless, and the tip is self-disinfecting. Disadvantages of electro-cautery include unavoidable burning, does not allow to use near the implants, dangerous in explosive environment, contraindicated in pacemakers.

\section{CONCLUSION}

From this study, our ENT Department has developed an excellent minimally invasive technique for ankyloglossia. Same technique can also be performed using LASER. But considering the cost factor, bipolar is found to be very potent. This procedure is superior due to its simplicity and gives all the required results in less time. This procedure can be done as a day care procedure. Expenditure is very minimal for the patient. Thus, this novel technique is superior to all the conventional surgical procedures.

\section{REFERENCES}

[1] Hooda A, Rathee M, Yadav SP, et al. Ankyloglossia: a review of current status. The Internet Journal of Otorhinolaryngology 2010;12(2).

[2] Horton CE, Crawford HH, Adamson JE, et al. Tonguetie. Cleft Palate J 1969;6:8-23. 
[3] Dunn P. Paulus Aegineta (625-690 AD) and Bysantine medicine. Archives of Disease in Childhood-Fetal and Neonatal Ed 1997;77(2):F155-F6.

[4] Sadler TW, Langman J. Langman's Medical embryology. 9th edn. Philadelphia: Wolters Kluwer Health/Lippincott Williams \& Wilkins 2012.

[5] Marchesan IQ. Lingual frenulum protocol. Int J Orofacial Myology 2012;38:89-103.

[6] Kendre SB, Shaikh AA, Kaur M, et al. Evaluation of anxiety and post-operational discomfort in frenectomy paediatric patients by comparing conventional method and laser application - a case report. Journal of Advanced Medical and Dental Sciences Research 2016;4(2):56-9.

[7] Breen S, Bradshaw C. Neonatal tongue tie: the effectiveness of intervention. J Pediatr Neonatal Care 2016;4(5):00154.

[8] Mossey P, Little J. Addressing the challenges of cleft lip and palate research in India. Indian Journal of Plastic Surgery: official publication of the Association of Plastic Surgeons of India 2009;Suppl 42:S9-S18.

[9] Gujrathi A, Ambulgekar V, Handal A. Surgical techniques for the treatment of tongue tie in children: a comparative study. International Journal of Otorhinolaryngology and Head and Neck Surgery 2016;2(3):128-34.

[10] Kotlow LA. Oral diagnosis of abnormal frenum attachments in neonates and infants: evaluation and treatment of the maxillary and lingual frenum using the Erbium: YAG laser. J Pediatr Dent Care 2004;10(3):11-4.

[11] Barot VJ, Vishnoi SL, Chandran S, et al. Laser: the torch of freedom for ankyloglossia. Indian Journal of Plastic Surgery: official publication of the Association of Plastic Surgeons of India 2014;47(3):418-22.
[12] Geddes DT, Kent JC, Mitoulas LR, et al. Tongue movement and intra-oral vacuum in breastfeeding infants. Early Human Development 2008;84(7):471-7.

[13] Bosma JF, Hepburn LG, Josell SD, et al. Ultrasound demonstration of tongue motions during suckle feeding. Developmental Medicine \& Child Neurology 1990;32(3):223-9.

[14] Burton P, Deng J, McDonald D, et al. Real-time 3D ultrasound imaging of infant tongue movements during breast-feeding. Early Human Development 2013;89(9):635-41.

[15] Billington J, Yardley I, Upadhyaya M. Long-term efficacy of a tongue tie service in improving breast feeding rates: a prospective study. Journal of Pediatric Surgery 2018;53(2):286-8.

[16] Koopmans-van Beinum FJ, van der Stelt JM. Early stages in the development of speech movements. In: Precursors of early speech. London: Palgrave Macmillan Publishing Company, 1986: p. 37-50.

[17] Hiiemae KM, Palmer JB. Tongue movements in feeding and speech. Critical Reviews in Oral Biology \& Medicine 2003;14(6):413-29.

[18] Sanguineti V, Laboissiere R, Payan Y. A control model of human tongue movements in speech. Biological Cybernetics 1997;77(1):11-22.

[19] Öhman SE. Numerical model of coarticulation. The Journal of the Acoustical Society of America. 1967;41(2):310-20.

[20] Sahin C. Treatment of ankyloglosia with coblation assisted surgery. Arch Otolaryngol \& Rhinol 2016;2(1):026-6. DOI: 10.17352/2455-1759.000017.

[21] Suter VG, Bornstein MM. Ankyloglossia: facts and myths in diagnosis and treatment. Journal of Periodontology 2009;80(8):1204-19.

[22] Memon MA. Surgical diathermy. Br J Hosp Med 1994;52(8):403-8. 